\title{
SINGLE UNIT PATTERNS DURING ANTICIPATORY BEHAVIOR ${ }^{1}$
}

\author{
James Olds, Walter D. Mink ${ }^{2}$ And Phillip J. Best ${ }^{3}$ \\ Department of Psychology, University of Michigan, Ann Arbor, Mich. 48104 (U.S.A.)
}

(Accepted for publication: June 10, 1968)

INTRODUCTION

The view that certain parts of the midbrain participate in determining the readiness of the animal and the intensity of its response is supported by a convergence of evidence even though there are grounds for debate about the actual mechanisms (Thompson 1967). The role of hippocampus in behavior is more problematic. At one extreme it is conceived as a subcortical counterweight to the "activating" reticular system (Parmeggiani 1967). At the other extreme it is conceived as an important part of the cortex involved in the integration of the emotions (Papez 1937) or the acquisition of memory traces (Milner 1958). The purpose of the present study was to bring neuronal activity in hippocampus and reticular formation and related structures under simultaneous observation during significant behavioral episodes permitting systematic variation in the readiness of the animal and in its motivational or mnemonic traces.

For this purpose, changes in spontaneous neuron spike activity were observed during brief, isometric, instrumental responses related to food or water. It was thought that if the rate of firing of neurons was correlated with the animal's readiness for the goal it would change as a function of the temporal proximity of the goal irrespective of whether food or water was being sought. If the rate was correlated instead with a motivational or mnemonic trace it would change

\footnotetext{
${ }^{1}$ Supported by research grants from the U.S. Public Health Service.

${ }^{2}$ NSF Science Faculty Fellow during part of the time of the research and USPHS Fellow during the other part. Present address: Dept. of Psychology, Macalester College, St. Paul, Minn. 55101.

3 NSF Post-doctoral Fellow.
}

as a function of the nature of the goal and would be relatively independent of time.

\section{METHODS}

The data reported were derived from 99 fixed probes consisting of fine wire (nichrome) micro-electrodes $(62.5 \mu)$ implanted chronically in twenty-four rats and categorized according

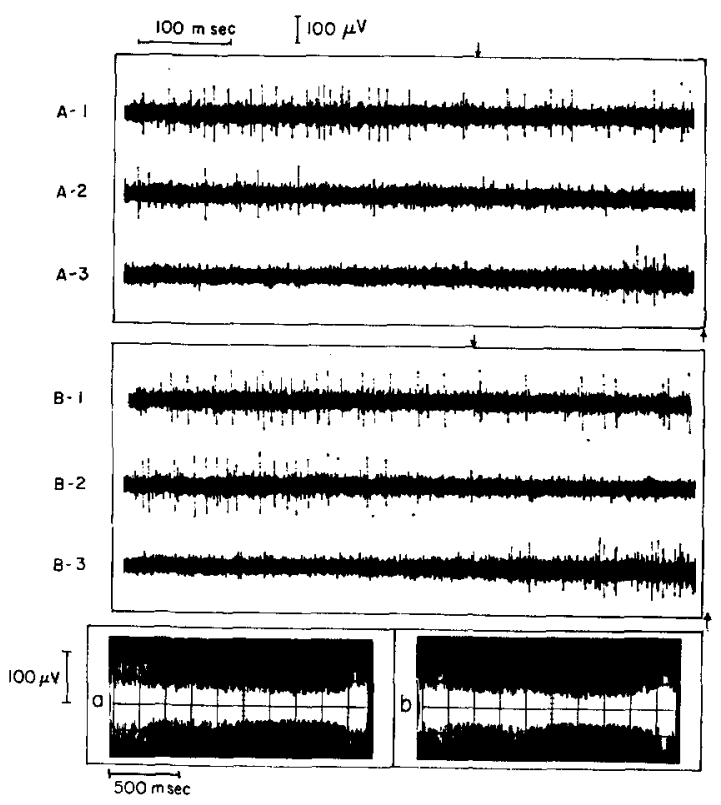

Fig. 1

Neuron activity recorded from a dorsal anterior part of the reticular formation near the posterior commissure. $A-1, A-2$, and $A-3$ represent a continuous $2 \mathrm{sec}$ waiting period terminated by a food reinforcement (at the second arrow). Movement after the first $250 \mathrm{msec}$ (the first arrow) would have caused cancellation of the reward. $B-1, B-2$ and $B-3$ represent a similar waiting period a few minutes later. Below: same data (slower time base) from $A$ in $a$, and from $B$ in $b$. Note a burst of spikes just prior to reinforcement and one early in the waiting period.

Electroenceph. clin. Neurophysiol., 1969, 26: 144-158 
to probe location as determined by histological verification after the experiments. Records were obtained in reference to an uninsulated, $250 \mu$ diameter wire placed at a depth of $5 \mathrm{~mm}$ in anterior cortex. There were 20 probes in hippocampal formation, 3 in corpus callosum, 18 in preoptic area, 14 in lateral hypothalamus, 8 in thalamus, 15 in dorsal reticular formation, 7 in ventromedial reticular formation, and 7 in a more ventro-medial area of tegmentum near interpeduncular nucleus, 3 in zona incerta, and 4 in medial hypothalamus. Differences between areas were tested for statistical reliability by non-parametric tests (Siegel 1956).
Rats were pre-trained to depress a pedal and then, after $0.25 \mathrm{sec}$, to arrest movement and to remain motionless for $1.75 \mathrm{sec}$ to obtain reward. There were two pedals, one for food and one for water. After training, simultaneous recordings were made from 4 or 5 probes in each animal. The recordings were made during 1.75 sec periods of waiting for food or water. The problem of movement and movement artifact was handled by tying a high-noise wire into the bundle of low-noise cables which connected the micro-electrodes via commutator and counterbalanced arm to the amplifiers. Its amplified signal portrayed clearly any movement on the

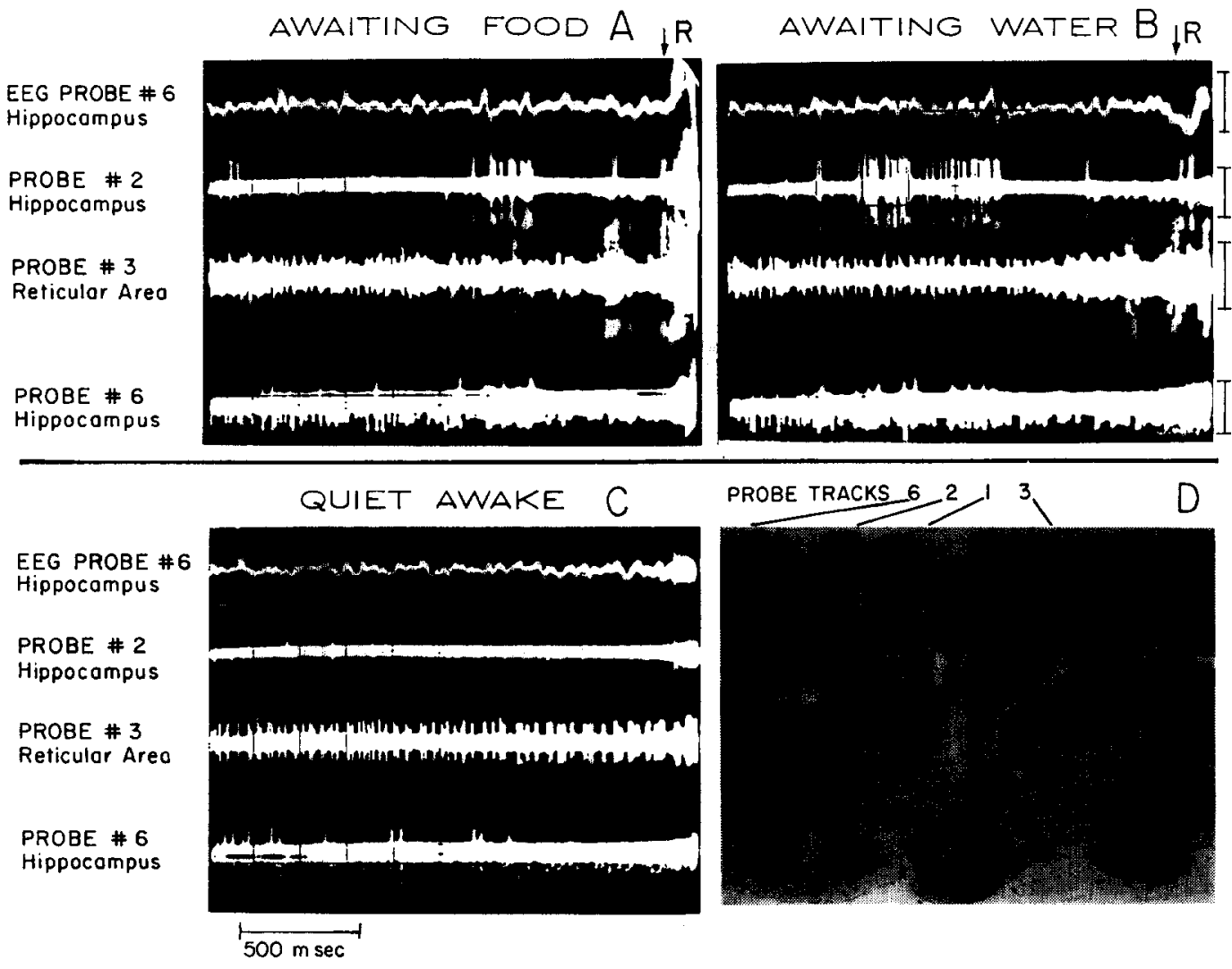

Fig. 2

Neuron activity and EEG samples and probe locations for one animal. In $A, B$ and $C$, there are single trials. The traces start as the animal depressed the pedal or at the beginning of a control trial. The reinforcement $(R)$ was presented near the end of the trace as indicated. The traces, held on the tube of a storage oscilloscope, were photographed inasmuch as they represent a successful trial without any movement during the last $1.75 \mathrm{sec}$. Note a burst of hippocampal activity during the food and water waiting periods. Also note an anticipatory burst of activity from the reticular area (channel 3 ) just prior to reinforcement. $D$ shows probe 6 in CA-4 of hippocampus, probe 2 in dentate gyrus, and probe 3 near posterior commissure; probe 1 , whose traces are not shown, was in CA-3 of hippocampus (it showed the largest food-water difference: $91 \%$ ). 
part of the animal. When activity above a low permissible level occurred on this channel during one of the brief periods, the data were automatically discarded and the reward was withheld. Data were taken continuously day and night; the tabulated data were averages for 4 days. Unit spikes were identified and counted automatically; when differences between units were too small, as was often the case, several were counted as if they were all members of the same class. Such classes were considered as single units for statistical analysis; they are called units in the text. There was only one class correlated with a given probe even though the unit identification device would have permitted more.

Because variability in absolute rates caused a corresponding variability in the observed changes, the actual rates were not used but only the changes and these were quantified in terms of ratios to mitigate the influence of absolute values. Rate differences between food and water waiting periods were stated as percentages of the smaller of the two. And the changes in rate from the beginning to the end of the last second of waiting were quantified by finding the slope of the straight line which best fitted the data and stating this slope as a percentage of the mean rate for the $1 \mathrm{sec}$ period. Thus a "slope" of 100 indicated that a change in firing rate equal to its mean value occurred during the last second of waiting.

\section{RESULTS}

Spikes of relatively constant amplitude (about $300 \mu \mathrm{V}$ ) were often observed (see Fig. 1). The duration of these was very short, rarely amounting to more than $400 \mu \mathrm{sec}$. When the micro-electrodes were being placed, these spikes would appear and disappear on movements of from 30 to $100 \mu$. In chronic preparations, spikes which appeared to originate from the same unit were observed often for periods of many days. Neuronal activity was characterized by periods of firing alternated with relatively silent intervals even in the course of brief observations (see Fig.

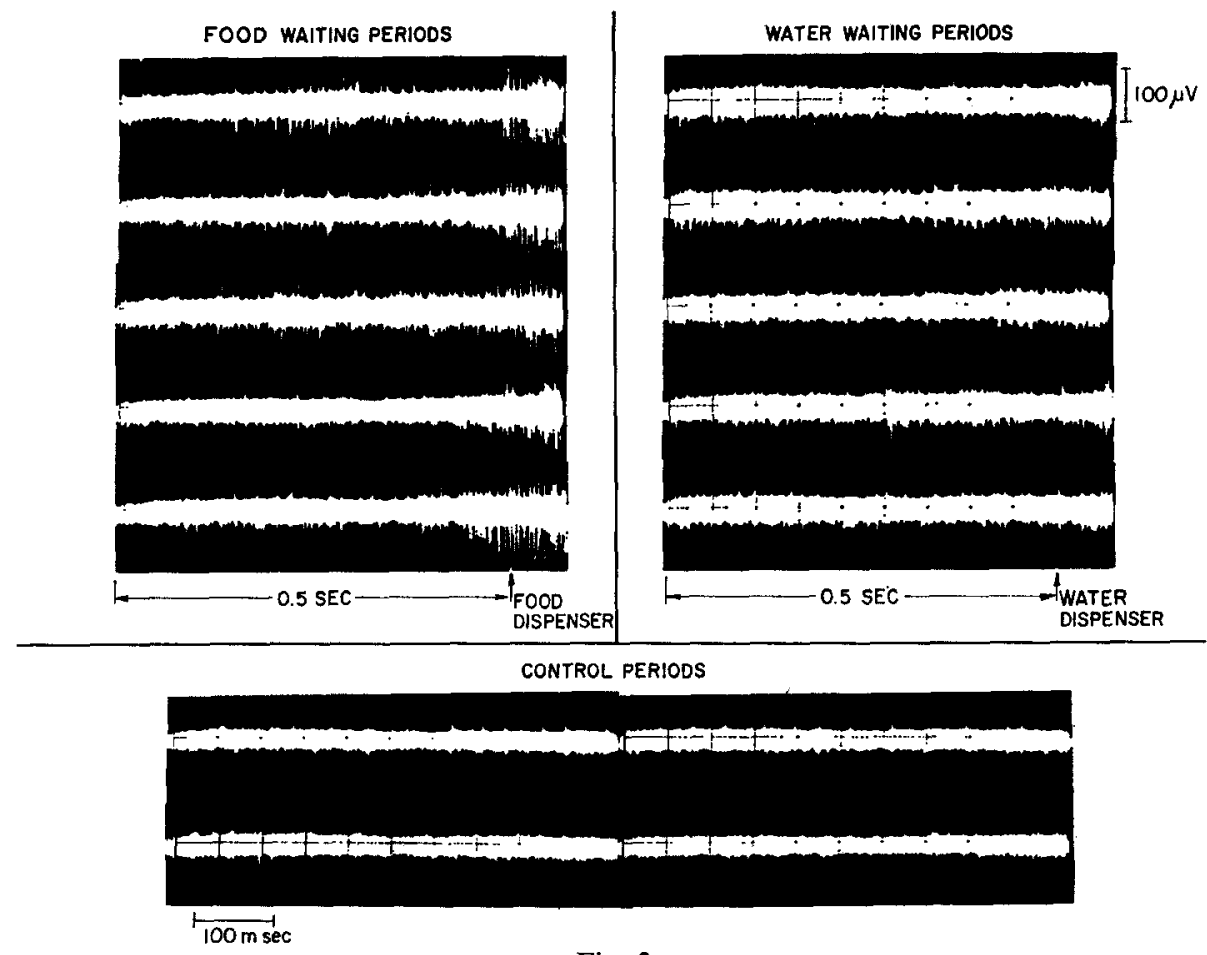

Fig. 3

Differential firing patterns in the last $0.5 \mathrm{sec}$ of food, water, and control periods from a unit in the dorsal reticular area. Note regular activity in control periods; faster and more random activity in food and water periods. Also note in food periods there was a rapid increase in rate during the last $0.5 \mathrm{sec}$. 


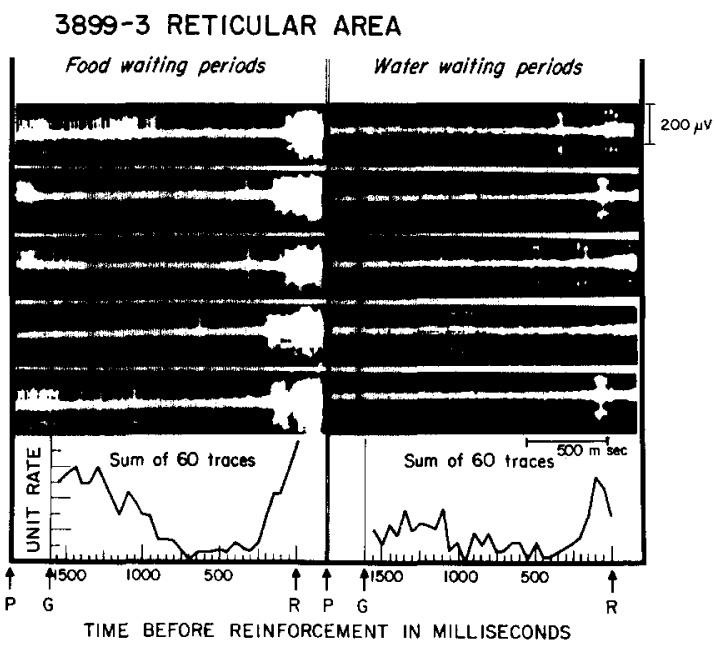

Fig. 4

Photographic documentation of the computer curves. For both food and water periods, five photographic samples of activity recorded from a reticular unit are shown and the computer sum of 60 such traces is shown below. In food traces a movement artifact after reinforcement obscures the terminal burst but there is no movement prior to the point marked $R$. Symbols are: $P=$ pedal depression $\mathrm{G}=$ electronic gate open and counting begins.

1). Changes in firing were noted in the course of the waiting intervals and consisted of a burst of spikes in mid-interval (Fig. 2, $A$ and $B$, second trace) or just prior to reinforcement (Fig. 2, $A$ and $B$, third trace) or of a gradual acceleration of spike frequency prior to reinforcement (Fig. 3, food periods), occasionally preceded by a decrease in firing rate (Fig. 4). These patterns were often stable for several hundred tests in the course of a day but variable from day to day. Certain firing characteristics, however, were often stable from day to day and even from probe to probe within a brain area (Fig. 5). They were categorized in terms of the degree of change from the beginning to the end of the last second of waiting. The most stable features (occasionally observed for more than one month) were the increments in firing rate prior to reinforcement in the dorsal reticular formation, the ventral regions of the tegmentum, and the thalamus. These changes are reflected in the positive "slopes" of Table I. Whereas this pattern was often quite similar for food and water (Tables I-A and I-B), it was sometimes attenuated (Fig. 5, C), or the firing rate might start increasing earlier in the waiting period (Fig. $5, D$ ) for one of the two incentives, or it might be present in the case of only one incentive (Fig. $5, A$ ). In the case of one unit, this "anticipatory" activity appeared at first only for food, but a month later appeared for both food and water although in an attenuated form with the latter incentive (Fig. 5).

The mean "slopes" (Table I) were not large in hippocampus, preoptic area, ventral reticular area of midbrain, or lateral hypothalamus, due to individual differences between units in these areas. Decremental changes during the last second were large and stable in the case of some units (Fig. 6, $A$ and $B$ ) while incremental changes were present in the case of others. There were also numerous cases in which neurons within the hippocampus and other structures would exhibit no particular change in their activity during this brief interval (Fig. 6, $C$ and $D$ ). The average change in hippocampus was nearly zero.

No units exhibiting decremental changes were observed in the dorsal reticular formation, ventral tegmentum, or thalamus; whereas $21 \%$ of the 58 units in other areas exhibited stable diminution in rate during the last second of food or water waiting periods (Table I).

The difference in "slope" between reticular formation units and hippocampus units in animals which had probes in both areas was tested for significance. Analyses of variance showed both food and water scores to differ between the two groups ( $P<0.025$ in both cases). "Slope" scores of dorsal reticular formation units were also compared for each animal which had probes in this area with average "slope" scores for all the other units in the same animal; the dorsal reticular formation "slope" was larger in fourteen of the fifteen animals $(P<0.001)$.

Water-food differences in average neuron rates during the waiting periods were large and stable in several cases (Table II). Large differences (of $50 \%$ or more) were most frequent in hippocampus; of 13 units exhibiting differences this large, 7 were in hippocampus, 3 in preoptic area, and 1 each in lateral hypothalamus, medial hypothalamus, and ventral tegmentum (Table II). Even in hippocampus, the proportion of stable differences; i.e., those persisting unchanged on all 4 days, was small. On the other hand, differences could be very large and prominent on one or more of the days (Fig. 6,D) even though they 


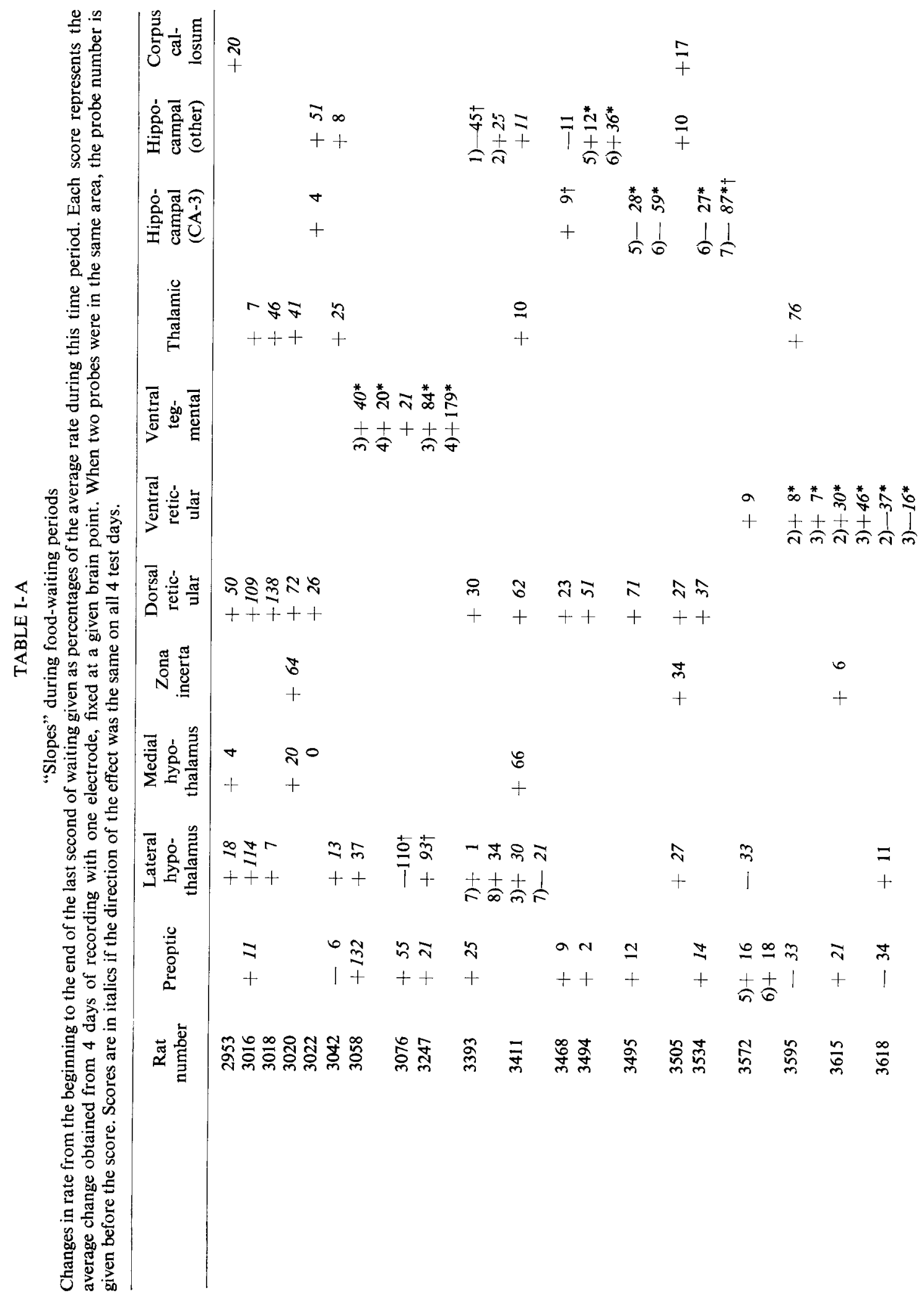




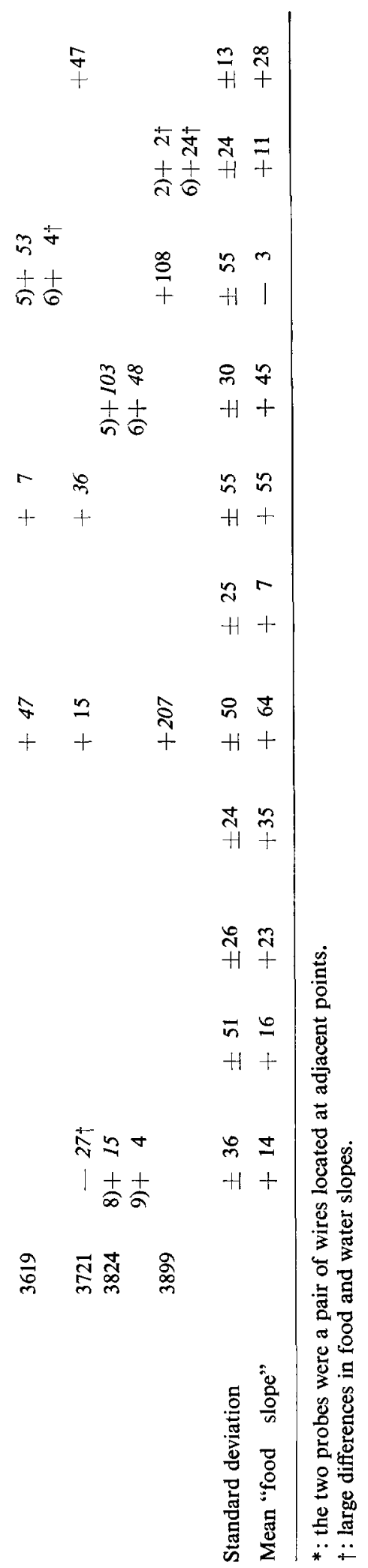

did not occur on all 4 days. Differences that were both large (above $50 \%$ ) and stable were very rare ( 7 in all: 3 in recordings from hippocampus, 3 from preoptic area, and 1 from ventral tegmentum - Table II). The largest of these was found in the hippocampus (Fig. 6, C), the control rate being more than doubled during food-waiting periods and cut to less than half in water-waiting periods.

In most instances of large, water-food differences in the rate of neuronal firing, the larger of the two rates occurred in the food-waiting periods. Yet there were exceptions and in one case the "water rate" was $342 \%$ of the "food rate" even though the probe was in the same part of the hippocampus where in another animal the food rate was $461 \%$ of the water rate (Fig. 6, C and $D$ ).

The findings, based on histological data, showed that 6 of 8 probes clearly in the anterior part of the reticular formation had very high slope scores (above 50\%- Fig. 7, $C$ and $D$ ). One very high score was also obtained from a point in or near the interstitial nucleus of the posterior commissure (Fig. 7, B). Probes farther forward (possibly in the thalamus) yielded intermediate scores (Fig. 7, A). Probes of the ventral reticular group (possibly in the red nucleus) yielded lower and variable slope scores (Fig. 7, $D$ ). Two moderate slope scores were derived from probes in the interpeduncular nucleus and a large score from the region between this nucleus and the medial lemniscus (Fig. 7, $C$ and $D$ ).

Five of the largest food-water differences appeared with probes in field CA-3 of hippocampus (Fig. 8).

In the hypothalamic region, the three probes yielding largest slope scores were found in or near the lateral aspect of the medial forebrain bundle in its ventral half. In two of these cases, there was a very large difference between the water and food slopes even though the waterfood differences in average neuron rate was small (see Fig. 9, $B$ and Table I). The two largest water-food differences in rate were observed with probes in the dorsal part of the dorsomedial nucleus and in the dorsomedial aspect of the medial forebrain bundle. Four other cases yielding water-food differences of $25 \%$ or more had probes in these same areas or in the nearby zona 


\section{TABLE I-B}

"Slopes" during water-waiting periods

(See Table I-A)

\begin{tabular}{|c|c|c|c|c|c|c|c|c|c|c|c|c|}
\hline & $\begin{array}{c}\text { Rat } \\
\text { number }\end{array}$ & Preoptic & $\begin{array}{c}\text { Lateral } \\
\text { hypo- } \\
\text { thalamic }\end{array}$ & $\begin{array}{l}\text { Medial } \\
\text { hypo- } \\
\text { thalamic }\end{array}$ & $\begin{array}{c}\text { Zona } \\
\text { incerta }\end{array}$ & $\begin{array}{c}\text { Dorsal } \\
\text { retic- } \\
\text { ular }\end{array}$ & $\begin{array}{c}\text { Ventral } \\
\text { retic- } \\
\text { ular }\end{array}$ & $\begin{array}{c}\text { Ventral } \\
\text { teg- } \\
\text { mental }\end{array}$ & Thalamic & $\begin{array}{l}\text { Hippo- } \\
\text { campal } \\
\text { (CA-3) }\end{array}$ & $\begin{array}{l}\text { Hippo- } \\
\text { campal } \\
\text { (other) }\end{array}$ & $\begin{array}{c}\text { Corpus } \\
\text { cal- } \\
\text { losum }\end{array}$ \\
\hline & 2953 & & +38 & +17 & & +110 & & & & & & +35 \\
\hline & 3016 & +6 & $\begin{array}{r}73 \\
+73\end{array}$ & & & $\begin{array}{r}1 \\
+\quad 89\end{array}$ & & & +13 & & & \\
\hline & 3018 & & -5 & & & $\begin{array}{l}1 \\
+59\end{array}$ & & & +36 & & & \\
\hline & 3020 & & & +63 & +116 & +65 & & & +66 & & & \\
\hline & 3022 & & & 0 & & $\begin{array}{r}1 \\
+\quad 29\end{array}$ & & & & -6 & +30 & \\
\hline & 3042 & -19 & +18 & & & & & & +38 & & -25 & \\
\hline & 3058 & +56 & $\begin{array}{r}1 \\
+29\end{array}$ & & & & & $\begin{array}{l}\text { 3) }+67^{*} \\
\text { 4) }+43^{*}\end{array}$ & & & & \\
\hline & 3076 & +31 & $+33 \dagger$ & & & & & +11 & & & & \\
\hline & 3247 & +22 & $-11 \dagger$ & & & & & $\begin{array}{l}\text { 3) }+45^{*} \\
4)+73^{*}\end{array}$ & & & & \\
\hline & 3393 & +37 & $\begin{array}{l}\text { 7) }-11 \\
8)-1\end{array}$ & & & +42 & & & & & $\begin{array}{l}\text { 1) }-2 \dagger \\
\text { 2) }+3\end{array}$ & \\
\hline & 3411 & & $\begin{array}{l}\text { 3) }+55 \\
\text { 7) }-88\end{array}$ & +41 & & +45 & & & +50 & & +23 & \\
\hline & 3468 & +6 & & & & +25 & & & & $+62 \dagger$ & +13 & \\
\hline & 3494 & $\begin{array}{l}T \\
-1\end{array}$ & & & & +109 & & & & & 5) $0^{*}$ & \\
\hline & & & & & & & & & & & $6)+3 *$ & \\
\hline & 3495 & -1 & & & & +9 & & & & 5) $-35^{*}$ & & \\
\hline & 305 & & & & & & & & & 6)- $-88^{*}$ & . & $+2 ?$ \\
\hline & $\begin{array}{l}3505 \\
3534\end{array}$ & +12 & +36 & & +63 & $\begin{array}{l}+38 \\
+15\end{array}$ & & & & 6)-17* & 0 & +22 \\
\hline & & & & & & & & & & 7) $-7 * f$ & & \\
\hline & 3572 & $5)-1$ & -15 & & & & -50 & & & & & \\
\hline & & 6) +4 & & & & & & & & & & \\
\hline & 3595 & -27 & & & & & $2)+14^{*}$ & & +53 & & & \\
\hline & & & & & & & $3)+4^{*}$ & & & & & \\
\hline & 3615 & +3 & & & +37 & & $2)+13^{*}$ & & & & & \\
\hline & & & & & & & 3) $+25^{*}$ & & & & & \\
\hline & 3618 & -46 & -14 & & & & 2) $0^{*}$ & & & & & \\
\hline & & & & & & & 3) & & & & & \\
\hline & 3619 & & & & & +68 & & +7 & & $5)+60$ & & \\
\hline & 3721 & $+22 \div$ & & & & +18 & & +39 & & & & +18 \\
\hline & 3824 & $8)+26$ & & & & & & & 5) +81 & & & \\
\hline & & 9) -13 & & & & & & & 6) +25 & & & \\
\hline & 3899 & & & & & +168 & & & & +60 & 2) $-69 \dagger$ & \\
\hline & & & & & & & & & & & 6) $-41 \dagger$ & \\
\hline Standard deviation & & \pm 24 & \pm 38 & \pm 24 & \pm 33 & \pm 43 & \pm 22 & \pm 23 & \pm 21 & \pm 53 & \pm 27 & \pm 7 \\
\hline Mean "water slope" & & +6 & +10 & +30 & +72 & +59 & 0 & +41 & +54 & +12 & -6 & +25 \\
\hline
\end{tabular}


1 ABLE 11

Water-food differences in rate

Each score represents the average 2 sec rate during water-waiting periods minus the average 2 sec rate during food-waiting periods, obtained from 4 days of recording with one electrode, fixed at a given brain point. The scores were normalized by converting the differences to a percentage of the smaller of the two scores. Scores are positive when the water rates were faster, negative when food rates were faster. See Table I-A

\begin{tabular}{|c|c|c|c|c|c|c|c|c|c|c|c|c|}
\hline & $\begin{array}{c}\text { Rat } \\
\text { number }\end{array}$ & Preoptic & $\begin{array}{l}\text { Lateral } \\
\text { hypo- } \\
\text { thalamic }\end{array}$ & $\begin{array}{c}\text { Medial } \\
\text { hypo- } \\
\text { thalamic }\end{array}$ & $\begin{array}{c}\text { Zona } \\
\text { incerta }\end{array}$ & $\begin{array}{c}\text { Dorsal } \\
\text { retic- } \\
\text { ular }\end{array}$ & $\begin{array}{c}\text { Ventral } \\
\text { retic- } \\
\text { ular }\end{array}$ & $\begin{array}{c}\text { Ventral } \\
\text { teg- } \\
\text { mental }\end{array}$ & Thalamic & $\begin{array}{l}\text { Hippo- } \\
\text { campal } \\
\text { (CA-3) }\end{array}$ & $\begin{array}{l}\text { Hippo- } \\
\text { campal } \\
\text { (other) }\end{array}$ & $\begin{array}{c}\text { Corpus } \\
\text { cal- } \\
\text { losum }\end{array}$ \\
\hline & 2953 & & -5 & +28 & & -45 & & & & & & -14 \\
\hline & 3016 & +8 & +3 & & & +14 & & & 0 & & & \\
\hline & 3018 & & +25 & & & +1 & & & -1 & & & \\
\hline & 3020 & & & -5 & -13 & -1 & & & -5 & & & \\
\hline & 3022 & & & +5 & & +1 & & & & -361 & +8 & \\
\hline & 3042 & +13 & +17 & & & & & & -1 & & -12 & \\
\hline & 3058 & +59 & +5 & & & & & $\begin{array}{l}3)+18^{*} \\
4)+24^{*}\end{array}$ & & & & \\
\hline & 3076 & +28 & +15 & & & & & +27 & & & & \\
\hline & 3247 & -2 & +3 & & & & & 3) $-51^{*}$ & & & & \\
\hline & & & & & & & & 4) $+3^{*}$ & & & & \\
\hline & 3393 & -93 & $\begin{array}{l}\text { 7) }+55 \\
8)-9\end{array}$ & & & -20 & & & & & $\begin{array}{l}\text { 1) }-70 \\
2)+8\end{array}$ & \\
\hline & 3411 & & $\begin{array}{l}3)+1 \\
7)+9\end{array}$ & +141 & & -2 & & & -8 & & -5 & \\
\hline & 3468 & +3 & & & & -16 & & & & +242 & -8 & \\
\hline & 3494 & -1 & & & & -18 & & & & & $\begin{array}{l}\text { 5) }+29^{*} \\
6)-16^{*}\end{array}$ & \\
\hline & 3495 & -15 & & & & -33 & & & & 5) $+12^{*}$ & & \\
\hline & 3505 & & -23 & & +31 & -16 & & & & & -51 & -14 \\
\hline & 3534 & +2 & & & & +5 & & & & $\begin{array}{l}\text { 6)+ } 12^{*} \\
7)-19^{*}\end{array}$ & & \\
\hline & 3572 & $\begin{array}{l}5)+58 \\
6)+9\end{array}$ & +1 & & & & +18 & & & & & \\
\hline & 3595 & +13 & & & & & $2)+5^{*}$ & & +32 & & & \\
\hline & & & & & & & 3) $+2 l^{*}$ & & & & & \\
\hline & 3615 & +2 & & & +28 & & 2) $+5^{*}$ & & & & & \\
\hline & & & & & & & 3) + 2* $^{*}$ & & & & & \\
\hline & 3618 & -20 & -7 & & & & 2) $-22^{*}$ & & & & & \\
\hline & & & & & & & 3) $-21^{*}$ & & & & & \\
\hline & 3619 & & & & & -18 & & +13 & & 5)- 54 & & \\
\hline & 3721 & +14 & & & & +35 & & -22 & & 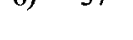 & & -21 \\
\hline & 3824 & $8)-15$ & & & & & & & 5) -8 & & & \\
\hline & & 9)-- 9 & & & & & & & $6)-4$ & & & \\
\hline & 3899 & & & & & $-4 I$ & & & & -91 & $\begin{array}{l}2)-8 \\
6)+1\end{array}$ & \\
\hline Standard deviation & & \pm 24 & \pm 14 & \pm 56 & \pm 8 & \pm 14 & \pm 8 & \pm 14 & \pm 10 & \pm 116 & \pm 21 & \pm 3 \\
\hline $\begin{array}{l}\text { Mean difference } \\
\text { (sign ignored) }\end{array}$ & & 21 & 13 & 45 & 24 & 18 & 13 & 23 & 7 & 96 & 20 & 16 \\
\hline
\end{tabular}



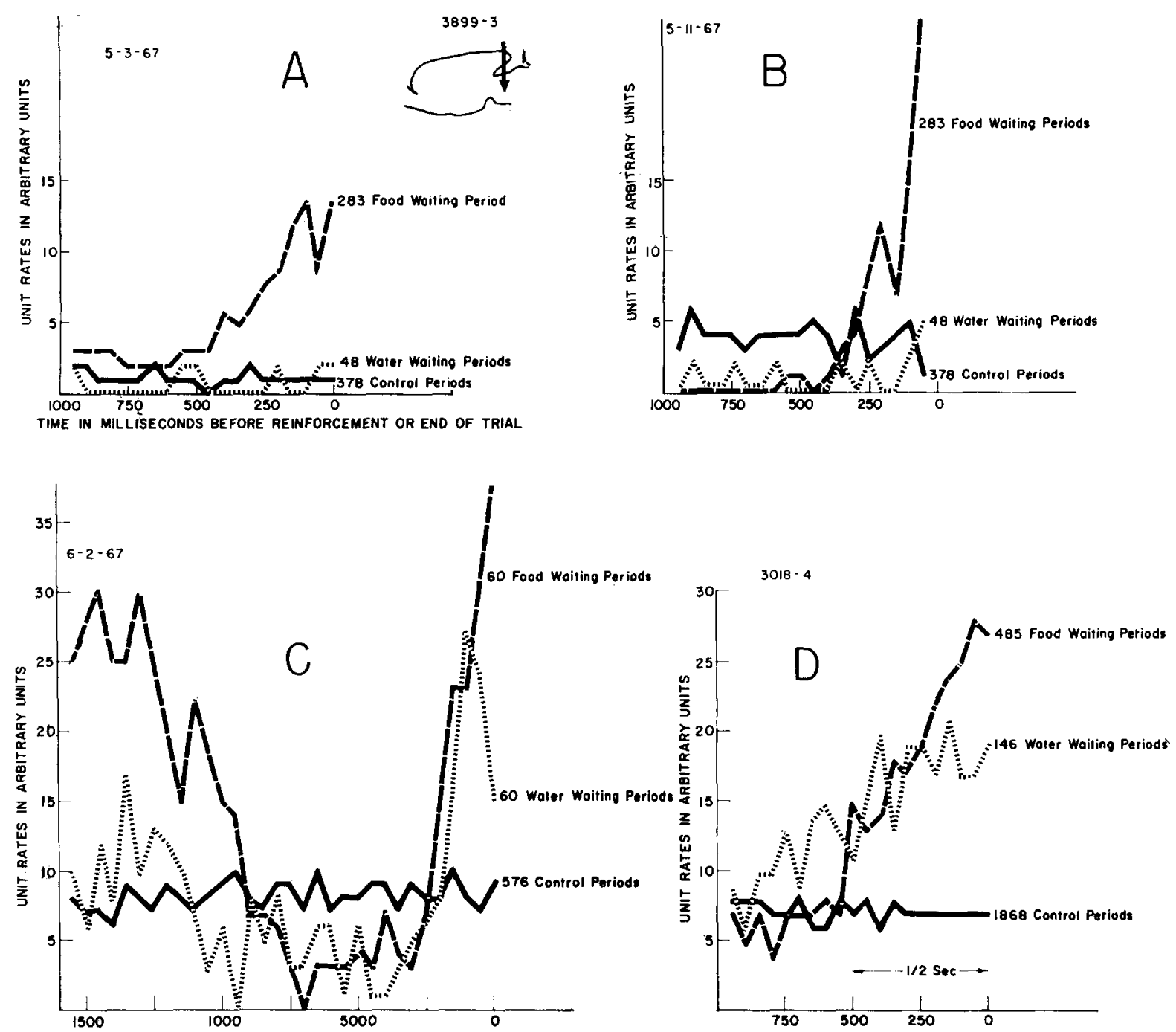

Fig. 5

Slopes in reticular formation. Each curve represents the averaged change of rate during the last part of the trials for a number of food, water, or control periods. $A, B$ and $C$ : data from the same reticular formation unit on 3 different days spread over the period of a month. Note a gradual increase in "anticipatory" neuronal activity prior to water reinforcement which did not, however, achieve the level of the food activity. $D$ : data from a different reticular formation unit in a different animal.

incerta (Fig. 9, $B$ and $C$ ). When probes were placed in more ventral parts of the hypothalamic region, water-food differences tended to be very small.

The three large water-food differences in preoptic area were obtained with probes located in a dorsal part of this area, about halfway between the medial and lateral components of the medial forebrain bundle. The probes were thus in or above the middle component.
In the thalamus, the highest slope scores appeared when probes were placed in a boundary area between ventral and lateral nuclei. Very low scores appeared when probes were placed in anterior areas. (Ventral and medial parts of the thalamus were poorly explored.)

\section{DISCUSSION}

Neuron spikes were recorded during an in-

Electroenceph. clin. Neurophysiol., 1969, 26: 144-158 

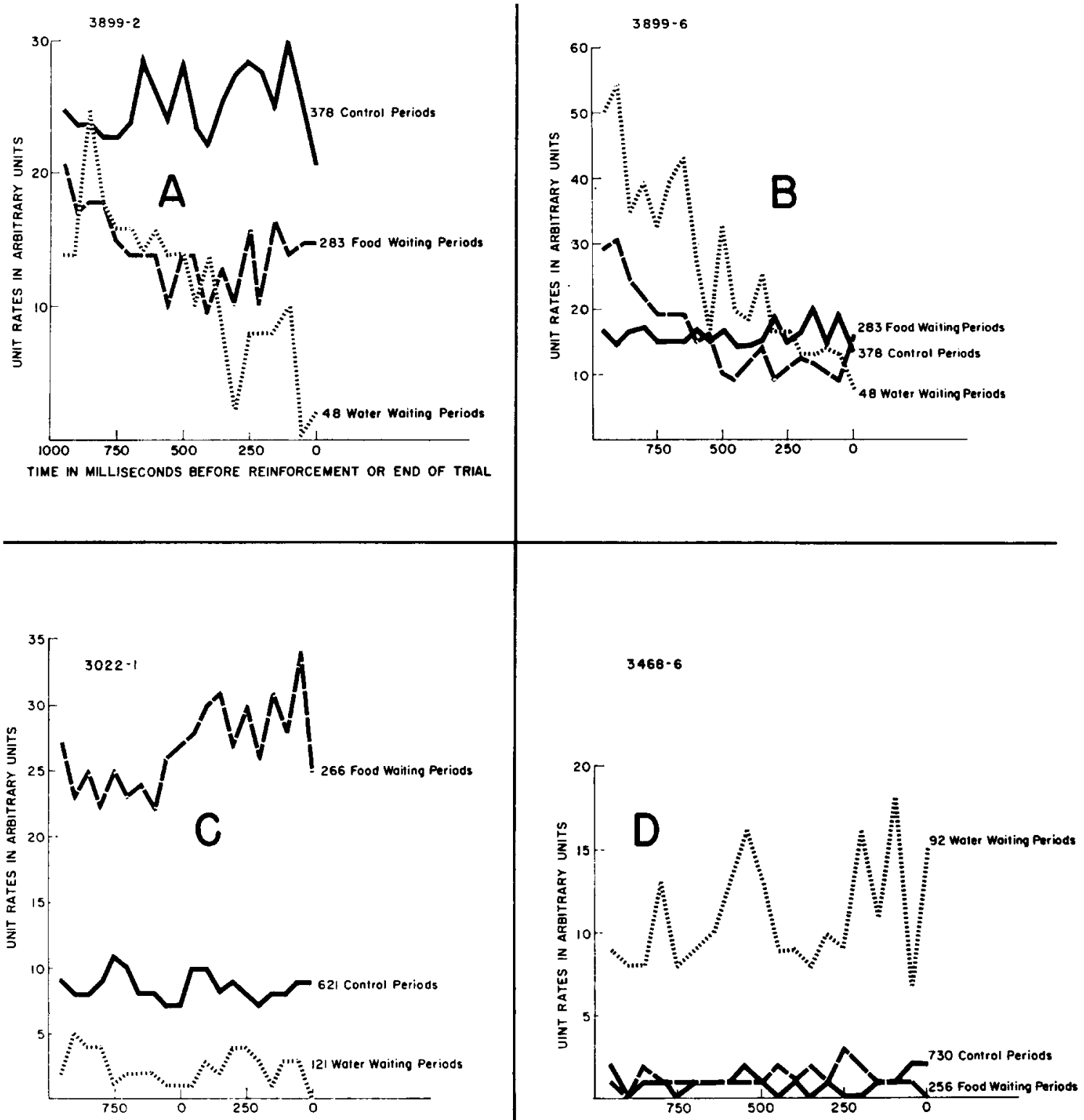

Fig. 6

Rapid changes in unit rates prior to reinforcement. Mean daily "slope" for 4 hippocampal neurons (in 3 animals). These are samples indicating the kind of patterns obtained; they do not in all cases represent the full 4 days of data as there was sometimes considerable variability in hippocampus from day to day. Note, in $A$ and $B$ (CA-4 and dentate gyrus respectively), a decline in neuron rates prior to reinforcement, and in $C$ and $D$ (both in CA-3) the neuron rates differed markedly depending on the incentive.

strumental response which had three main characteristics: it was motionless, it implied a tonic posture and was an extensor response.

During the holding period, neuron activity recorded from the reticular formation exhibited a relatively dependable change. During the last second of holding, there was regularly an acceleration, which rose to a maximum just prior to the point in time where reinforcement was applied and before the onset of consummatory behavior. 


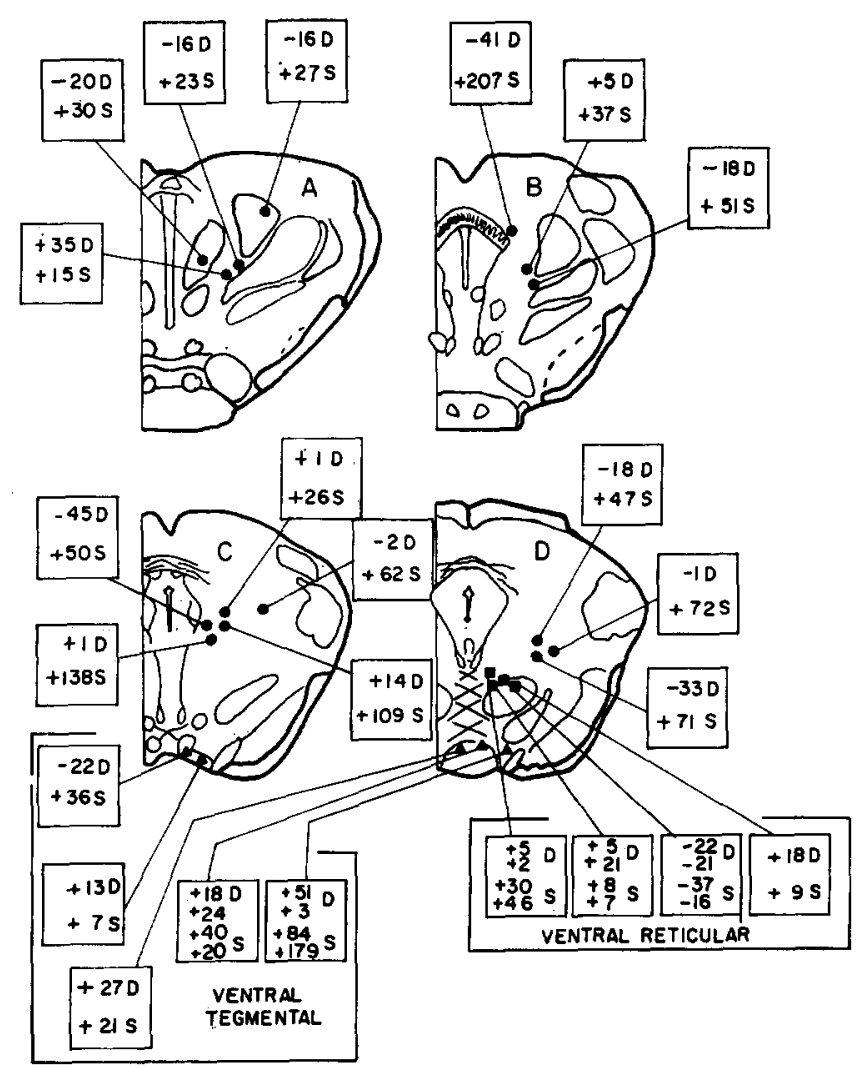

Fig. 7

Midbrain map. Location of probes in dorsal reticular group ( $\bullet$ ), ventral reticular group ( $\mathbf{\square}$ ), and ventral tegmental group (A). Probes are identified by water-food difference (D) and slope of the food curve over the last second of waiting (S). When a pair of probes was placed proximally at the "same" brain point, both sets of scores are given.

The acceleration in neuronal firing rate was relatively unrelated to the particular incentive involved and it was similar in different units and in different structures within the anterior part of the midbrain reticular formation and the intralaminar area of the thalamus.

Likely correlates of this acceleration would include: (1) a change in arousal level; (2) an anticipatory representation of the goal object; (3) an intentional process; (4) an inhibitory process; (5) a tonic response; and (6) a neuromuscular preparatory response related to the ensuing capture. The non-specific ones among these factors such as (1), (4), (5) and possibly (6) would most likely be related to the reticular formation of the midbrain and the thalamus. Because detectable movement by the animal occurred very rapidly (within $50 \mathrm{msec}$ ) after the auditory report of the reinforcement mechanism, a state of intense readiness had to be assumed. This made it appealing to ascribe the acceleration in neuronal firing to an interaction of two descending processes, one maintaining the isometric extensor response; e.g., (4) and (5), and the other creating a neuromuscular readiness; e.g., (6). These data, therefore, seemed to support the idea of a diffuse, descending, excitatory and/or inhibitory system represented in the rostral part of the midbrain and in non-specific parts of the thalamus.

During these same periods of instrumental behavior without movement neuronal activity in hippocampus and its related structures was more variable. There was an orderly decremental process in the firing rates of some hippocampal neurons, an orderly incremental process in others, while in still a third group there was a stable 

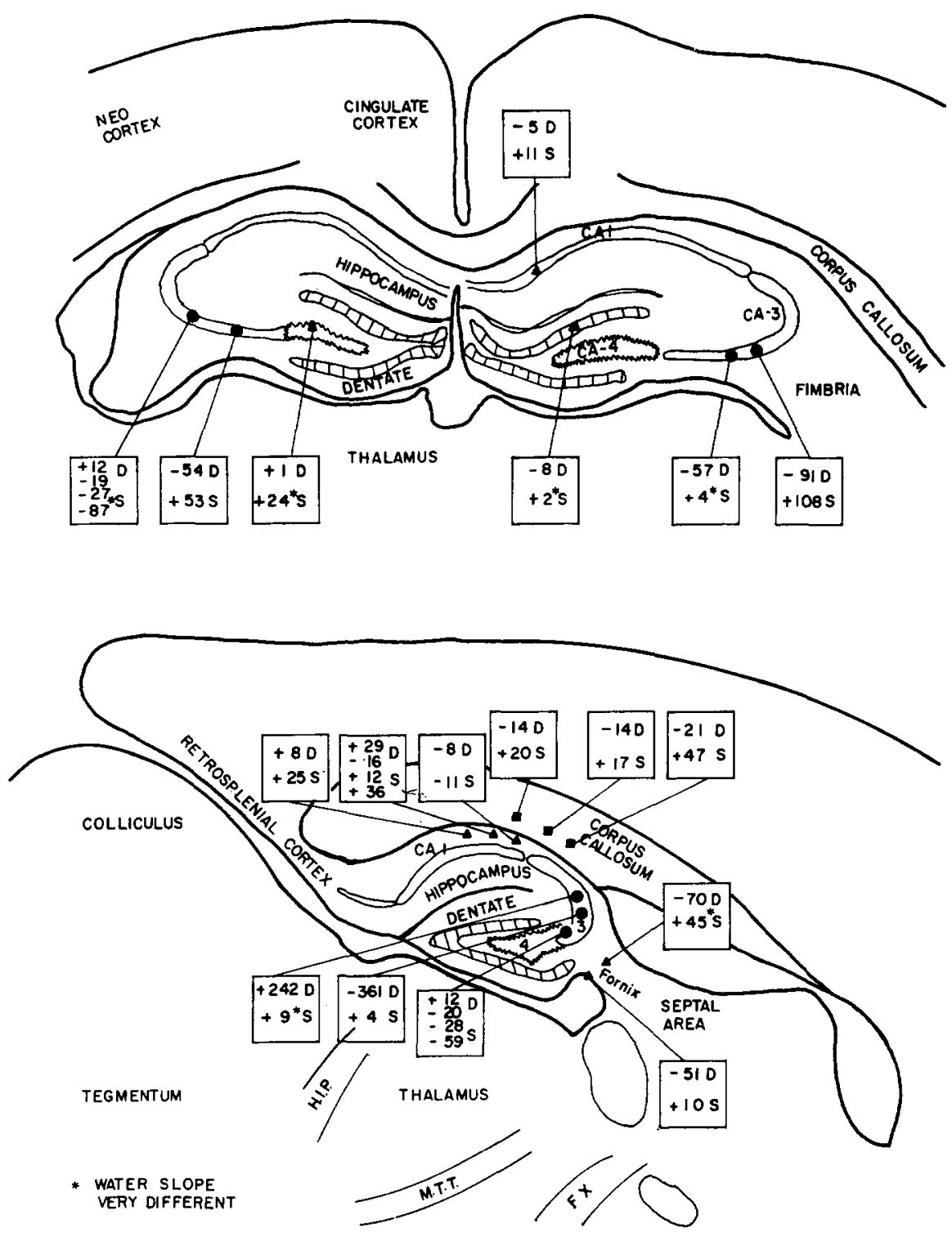

Fig. 8

Hippocampal map. Location of probes in the three fields of the hippocampus (1,3 and 4), in the dentate gyrus, in the fornix, and in nearby corpus callosum. Probes are identified as in the previous figure. Symbols are: $\boldsymbol{\Theta}$, hippocampus $\mathrm{CA}-3 ; \boldsymbol{\Lambda}$, hippocampus other; $\boldsymbol{\nabla}$, corpus callosum.

correlate of the incentive during the course of the observation period.

The five very large food-water differences in neuronal firing rate within the CA-3 sector of the hippocampus, and the relative absence of these differences elsewhere in the hippocampus or in the other structures represent a finding worth noting in spite of the small number of observa- tions. The fact that a change in firing rate in the hippocampus would appear, sometimes, in almost all-or-nothing fashion during one of the two waiting intervals (food or water) and be absent during the other, yet, a day or so later the difference would disappear or even reverse, seemed to suggest a "temporary representation", similar perhaps to the "memories" which are 


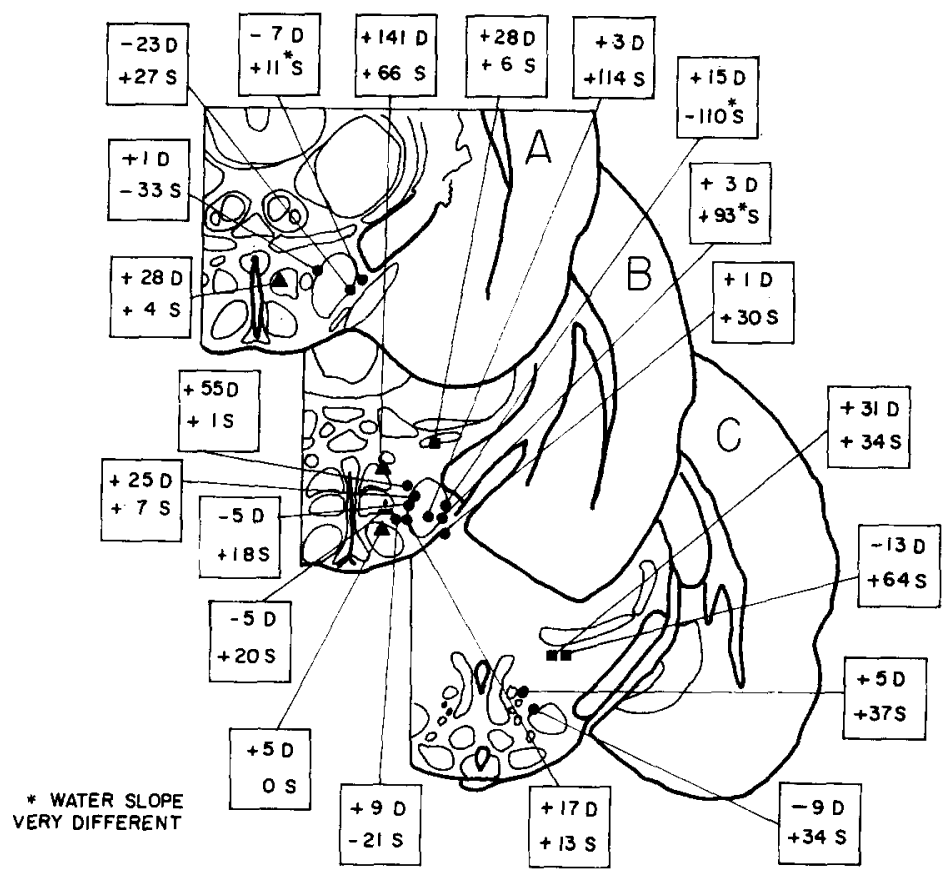

Fig. 9

Hypothalamic map. Location of probes in lateral hypothalamus, medial hypothalamus, and zona incerta. Probes are identified as in previous figures. Symbols are: $\mathbf{0}$, lateral hypothalamic area; $\boldsymbol{\Lambda}$, medial hypothalamus; $\mathbf{n}$, zona incerta.

stored in the "words" of a computer memory and later erased.

The few hippocampal neurons whose pattern of activity appeared to represent an inversion of the reticular formation patterns provided some support for the view of the hippocampus as a subcortical, inhibitory counterbalance for the reticular formation. However, the variability of hippocampal patterns and the larger number of neurons whose firing was correlated with the motivational states or mnemonic traces were more in keeping with the conception of the hippocampus as a part of the cortex.

Specific patterns in motor cortex were found to be correlated with specific motor behavior by Evarts (1966). The observation of a non-specific "conditioned response" in midbrain seems to be in accord with the work of Buchwald et al. (1966); its incremental slope as the animal approached the goal was anticipated by the EEG observations of Yoshii and Tsukiyama (1952); and its dissociation from overt skeletal movements is compatible with the findings of Ellison et al. (in press). The possibility of unit patterns related to particular kinds of unconditioned stimuli was suggested by the work of Travis and Sparks (1967).

The observation of differing patterns of activity derived from neighboring hippocampal neurons during a period of instrumental behavior has some relation to the findings of John and Killam (1959), Adey et al. (1960, 1962), Lissák and Grastyán (1960) and Grastyán et al. (1966) who found hippocampal theta to be correlated with the orientation of a motivationally relevant stimulus or with some other aspect of the instrumental process. The variable pattern of the hippocampal neuronal behavior observed in our experiments might help to account for the fact that some observers (Ellison et al., in press) have not found theta activity during the instrumental period, particularly when there was no concomitant movement.

\section{SUMMARY}

1. Animals with several fine-wire electrodes 
implanted chronically in the brain for single unit recordings were pre-trained to immobilize themselves for brief intervals in order to obtain food or water. Unit activity was recorded simultaneously from 4 probes in each animal during these periods of immobilization and in other quiet intervals during wakefulness and sleep. Groups of from 7 to 20 probes were studied in each of the following areas: hippocampal, preoptic, lateral hypothalamic, ventral tegmental, thalamic, ventral reticular and dorsal reticular.

2. Relatively large and stable changes in neuronal activity were noted in the course of the brief waiting periods. In dorsal reticular formation, thalamus and ventral tegmentum changes were regularly in the positive direction, neurons firing more rapidly as the reinforcing stimulus became more imminent. In the neuronal activity of hippocampus, preoptic area, ventral reticular. formation and hypothalamus, there was more variability between neurons; the firing rate would show either a decrement or on increment or no change depending on the particular unit involved.

3. In individual experiments the activity of some neurons seemed to be especially related to either food or water behavior; these elements were more frequently found in the hippocampus, hypothalamus and preoptic area, the largest number appearing in area CA-3 of hippocampus.

\section{RÉSUMÉ}

\section{ACTIVITÉ D'UNITÉS CELLULAIRES ISOLÉES PENDANT LE COMPORTEMENT D'ANTICIPATION}

1. Des animaux porteurs de plusieurs électrodes métalliques fines implantées chroniquement dans le cerveau pour enregistrer des unités cellulaires ont été préalablement entraînés à s'immobiliser pendant de brefs intervalles afin d'obtenir de la nourriture ou de l'eau. Chez chaque animal, l'activité unitaire est enregistrée simultanément à partir de 4 sondes au cours de ces périodes d'immobilisation et d'autres intervalles de repos à l'état de veille et de sommeil. Des groupes de 7 à 20 électrodes ont été étudiés dans chacune des aires suivantes: hippocampe, aire préoptique, hypothalamus latéral, tegmentum ventral, thalamus, aires réticulée ventrale et réticulée dorsale.

2. Des changements relativement importants et stables de l'activité neuronique sont notés au cours des brèves périodes d'attente. Dans la formation réticulaire dorsale, le thalamus et le tegmentum ventral, ces modifications se font régulièrement dans le sens positif, les neurones se déchargeant de façon plus rapide lorsque le stimulus de renforcement devient plus imminent. Dans l'activité neuronique de l'hippocampe, de l'aire préoptique, de la formation réticulaire ventrale et de l'hypothalamus, on note davantage de variabilité entre les neurones: le taux de décharge montre, soit une diminution, soit une augmentation, soit une absence de changement, suivant l'unité cellulaire particulière impliquée.

3. Dans certaines expériences individuelles, l'activité de quelques neurones apparaît liée tout spécialement au comportement d'attente, soit de la nourriture, soit de l'eau; ces éléments sont plus fréquemment rencontrés au niveau de l'hippocampe, de l'hypothalamus et de l'aire préoptique, le plus grand nombre d'entre eux apparaissant dans l'aire CA-3 de l'hippocampe.

The authors are grateful for technical assistance to G. Baldrighi, W. E. Wetzel, H. J. Frey and W. J. Allan.

\section{REFERENCES}

Adey, W. R., Dunlop, C. W. and Hendrix, C. E. Hippocampal slow waves. Distribution and phase relationships in the course of approach learning. Arch. Neurol. (Chic.), 1960, 3: 74-90.

Adey, W. R., WALTer, D. O. and LindsLey, D. F. Subthalamic lesions. Effects on learned behavior and correlated hippocampal and subcortical slow wave activity. Arch. Neurol. (Chic.), 1962, 6: 194-207.

Buchwald, J. S., Halas, E. S. and Schramm, S. Changes in cortical and subcortical unit activity during behavioral conditioning. Physiol. and Behavior, 1966, 1: 11-22.

Ellison, G. D., Humphrey, G. L. and Feeney, D. Some electrophysiological correlates of two behavioral states. J. comp. physiol. Psychol. (in press).

EvarTs, E. V. Pyramidal tract activity associated with a conditioned hand movement in the monkey. $J$. Neurophysiol., 1966, 29: 1011-1027.

Grastyán, E., Karmos, G., Vereczkey, L. and KelléNyi, L. The hippocampal electrical correlates of the homeostatic regulation of motivation. Electroenceph. clin. Neurophysiol., 1966, 21: 34-53.

JoHN, E. R. and KILlaM, K. F. Electrophysiological correlates of avoidance conditioning in the cat. $J$. Pharmacol. exp. Ther., 1959, 125: 252-274.

LisSÁK, K. and GRASTYÁn, E. The changes of hippocampal electric activity during conditioning. Electroenceph. clin. Neurophysiol., 1960, Suppl. 13: 271-279. 
Milner, B. Psychological defects produced by temporal lobe excision. Res. Pub. Ass. nerv. ment. Dis., 1958, 36 : 244-257.

PAPEZ, J. W. A proposed mechanism of emotion. Arch. Neurol. Psychiat. (Chic.), 1937, 38: 725-743.

Parmeggiani, P. P. On the functional significance of the hippocampal thetarhythmn. In W. R. ADEY and T. TOKIZANE (Eds.), Structure and function of the limbic system. Progress in brain research, Vol. 27. Elsevier, Amsterdam, 1967: 413-441.
SIEGEL, S. Nonparametric statistics for the behavioral sciences. McGraw-Hill, New York, 1956, 312 p.

THOMPSON, R. F. Foundation of physiological psychology. Harper and Row, New York, 1967: 413-418.

Travis, R. P. and Sparks, D. L. Changes in unit activity during stimuli associated with food and shock reinforcement. Physiol. and Behavior, 1967, 2: 171-177.

YoshiI, N. and TsukiYama, K. Electroencephalographic studies on conditioned behavior of white rat. Jap. $J$. Physiol., 1952, 2: 186-193.

Reference: OLDS, J., MINK, W. D. and BEST, P. J. Single unit patterns during anticipatory behavior. Electroenceph. clin. Neurophysiol., 1969, 26: 144-158. 